Check for updates

Cite this: RSC Adv., 2017, 7, 28542

Received 5th April 2017

Accepted 22nd May 2017

DOI: $10.1039 / c 7 r a 03864 j$

rsc.li/rsc-advances

\section{Synthesis and gas sensing properties of molybdenum oxide modified tungsten oxide microstructures for ppb-level hydrogen sulphide detection}

\begin{abstract}
Jie Hu, (D) *a Yongjiao Sun, ${ }^{a}$ Xiu Wang, ${ }^{a}$ Lin Chen, ${ }^{\text {b }}$ Wengdong Zhang ${ }^{\mathrm{a}}$ and Yong Chen ${ }^{\mathrm{c}}$
Flower-like molybdenum oxideatungsten oxide $\left(\mathrm{MoO}_{3}\left(\mathrm{CWO}_{3}\right)\right.$ composite microstructures were successfully synthesized by hydrothermal and impregnation methods. The fabricated samples were characterized by XRD, EDS, SEM and TEM, and the results show that the $\mathrm{MoO}_{3} \mathrm{CWO}_{3}$ composite is composed of crystallized nanosheets with a thickness of about $40 \mathrm{~nm}$. The gas sensing properties of the $\mathrm{MoO}_{3} \mathrm{aWO}_{3}$ composite microstructures towards hydrogen sulfide $\left(\mathrm{H}_{2} \mathrm{~S}\right)$ were investigated as a function of operating temperature and gas concentration. The gas sensors based on $\mathrm{MoO}_{3} \mathrm{CWO}_{3}$ composites show better sensing performances than that of a pure one. Moreover, the $\mathrm{Mo}_{6} \mathrm{~W}$-based gas sensor


detection limit $(20 \mathrm{ppb})$ and good selectivity at optimum operating temperature $\left(250{ }^{\circ} \mathrm{C}\right)$. Such an excellent performance can be attributed to the heterojunction between $\mathrm{MoO}_{3}$ and $\mathrm{WO}_{3}$.
\end{abstract}

\section{Introduction}

Hydrogen sulphide $\left(\mathrm{H}_{2} \mathrm{~S}\right)$, a colorless gas with a foul odor of rotten eggs, is harmful to human health and the environment. ${ }^{1}$ Usually, $\mathrm{H}_{2} \mathrm{~S}$ is produced during industrial processes such as oil and natural gas drilling and refining, sewage treatment and paper milling. The threshold limit of $\mathrm{H}_{2} \mathrm{~S}$ in the atmosphere defined by American Conference of Government Industrial Hygienists is $10 \mathrm{ppm}^{2}$ Therefore, it is necessary to develop a highly sensitive gas sensor for low concentration $\mathrm{H}_{2} \mathrm{~S}$ detection in the environment. ${ }^{3}$

Over the past few decades, many methods have been reported on developing novel gas sensors to detect the toxic gases. $^{4-6}$ Especially, the gas sensors based on metal oxide semiconductor are the most promising candidates for toxic gases detecting due to their outstanding advantages including high sensibility, low power consumption, quick response and minitype. ${ }^{7}$ Up to now, a large number of metal oxide semiconductors such as $\mathrm{SnO}_{2}, \mathrm{ZnO}, \mathrm{Fe}_{2} \mathrm{O}_{3}, \mathrm{In}_{2} \mathrm{O}_{3}, \mathrm{NiO}$, and $\mathrm{WO}_{3}$ (ref.

${ }^{a}$ Micro and Nano System Research Center, Key Lab of Advanced Transducers and Intelligent Control System (Ministry of Education), College of Information Engineering, Taiyuan University of Technology, Taiyuan 030024, Shanxi, China. E-mail: hujie@tyut.edu.cn

${ }^{b}$ Research Center on Advanced Materials Science and Technology, Taiyuan University of Technology, Taiyuan 030024, Shanxi, China

${ }^{c}$ Ecole Normale Supérieure-PSL Research University, Département de Chimie, Sorbonne Universités - UPMC Univ Paris 06, CNRS UMR 8640 PASTEUR, 24, rue Lhomond, 75005 Paris, France
8-15) have been widely used as gas sensing materials because of their tunable dimension and structures.

Among various materials, tungsten oxide $\left(\mathrm{WO}_{3}\right)$ has great potential for gas sensing. ${ }^{16,17}$ While, the efficiency of pure $\mathrm{WO}_{3}$ is insufficient for practice uses due to the low sensitivity and long response time. ${ }^{18}$ Recently, tremendous efforts have been made to explore $\mathrm{WO}_{3}$ composites, which exhibited numerous advantages in gas sensing performance such as high response, fast response and good selectivity. ${ }^{19-21}$ For example, Kim et al. ${ }^{\mathbf{1 3}}$ synthesized $\mathrm{RuO}_{2}$ nanoparticles loaded $\mathrm{WO}_{3}$ nanofibers using catalytic synthesis and functionalization method using apoferritin. The gas sensor using $\mathrm{RuO}_{2}$-functionalized $\mathrm{WO}_{3}$ nanofibers showed a significantly enhanced sensing response, which was 7.4 times higher than that of pristine $\mathrm{WO}_{3}$. Yao et al. ${ }^{\mathbf{1 4}}$ fabricated $\mathrm{Ag}$ nanoparticle-sensitized $\mathrm{WO}_{3}$ hollow nanospheres via a simple sonochemical synthesis route. The results displayed that the $\mathrm{Ag}$ nanoparticle-sensitized $\mathrm{WO}_{3}$ hollow nanospheres exhibits a lower operating temperature of $230{ }^{\circ} \mathrm{C}$, a faster response of $7 \mathrm{~s}$ and a superior detection limit of 0.09 ppb toward alcohol vapor. Kida et al. ${ }^{15}$ reported highly sensitive $\mathrm{NO}_{2}$ sensors using $\mathrm{SnO}_{2}$-functionalized $\mathrm{WO}_{3}$ nanolamellae by an acidification method. The $\mathrm{WO}_{3}-\mathrm{SnO}_{2}$ composites displayed an enhanced sensitivity of 370 to $200 \mathrm{ppb} \mathrm{NO}_{2}$. Up to now, although considerable efforts have been devoted to the $\mathrm{WO}_{3}$ composites, few of them focus on the flower-like $\mathrm{MoO}_{3} @ \mathrm{WO}_{3}$ composites and optimize the content of $\mathrm{MoO}_{3}$ for $\mathrm{H}_{2} \mathrm{~S}$ detection.

In this work, we successfully prepared special flower-like $\mathrm{MoO}_{3} @ \mathrm{WO}_{3}$ composite with various Mo contents by facile 
hydrothermal and impregnation method. The gas sensing properties of $\mathrm{MoO}_{3} @ \mathrm{WO}_{3}$ gas sensors were investigated under different operating temperatures. As expected, the gas sensors based on $\mathrm{MoO}_{3} @ \mathrm{WO}_{3}$ sensors exhibit enhanced gas sensing performance compared with that of pure one. Especially, the asprepared $\mathrm{Mo}_{6} \mathrm{~W}$ sensor shows an excellent gas sensing performance toward $\mathrm{H}_{2} \mathrm{~S}$ including high response, fast response/ recovery time, low limit of detection, and excellent selectivity. The improvement of gas sensing performance of $\mathrm{MoO}_{3} @ \mathrm{WO}_{3}$ composites can be attributed both to the particular structure as well as the heterojunction.

\section{Materials and methods}

\subsection{Preparation and characterization}

All chemicals are analytical grade and used as received without further purification. Pure $\mathrm{WO}_{3}$ microstructures were synthesized by the hydrothermal method. In brief, $0.4 \mathrm{~g}$ of tungsten hexachloride $\left(\mathrm{WCl}_{6}>\mathbf{9 9 . 9 \%}\right.$, Aladdin) was dissolved into $40 \mathrm{~mL}$ of ethanol through vigorous stirring for $30 \mathrm{~min}$. Then, the solution was transferred into a Teflon autoclave and heated at $160{ }^{\circ} \mathrm{C}$ for $24 \mathrm{~h}$. The resulting product was washed with distilled water, collected via centrifugation, dried at $80{ }^{\circ} \mathrm{C}$ for $10 \mathrm{~h}$ and calcined at $500{ }^{\circ} \mathrm{C}$ in air for $2 \mathrm{~h}$ to obtain a high crystalline phase.

A series of $\mathrm{MoO}_{3} @ \mathrm{WO}_{3}$ composite microstructures $\left(\mathrm{Mo}_{x} \mathrm{~W}, x\right.$ $=2,4,6,8$, correspondingly to the weight percentage of Mo element in the solution) were also prepared through a simple impregnation method, and the process is described as follows: a definite amount of ammonium heptamolybdate tetrahydrate $\left(\left(\mathrm{NH}_{4}\right)_{6} \mathrm{Mo}_{7} \mathrm{O}_{24} \cdot 4 \mathrm{H}_{2} \mathrm{O}>99.0 \%\right.$, Aladdin $)$ were dissolved into 10 $\mathrm{mL}$ of deionized water. After that, $0.5 \mathrm{~g}$ of the $\mathrm{WO}_{3}$ powders was dispersed in the solutions with different content of Mo under continuous magnetic stirring at $80{ }^{\circ} \mathrm{C}$ for $5 \mathrm{~h}$. Finally, the obtained precipitates were washed with ethanol several times and centrifugated, dried and calcined at $500{ }^{\circ} \mathrm{C}$ for $2 \mathrm{~h}$. The crystal structural, morphology and chemical component of the nanostructures were characterized by X-ray diffraction (XRD, Haoyuan), scanning electron microscopy (SEM, JSM-7001F), transmission electron microscopy (TEM, JEM-2100F), and energy dispersive spectrometer (EDS, Quantas200), respectively.

\subsection{Fabrication and measurement of gas sensors}

The $\mathrm{MoO}_{3} @ \mathrm{WO}_{3}$ composite gas sensors were fabricated as follows: the calcined samples were firstly mixed with a suitable amount of deionized water to form a paste. After that, the paste was coated on the ceramic tubes carefully to form sensing film. Then, a Ni-Cr heating wire was inserted in the tube to form a side heated gas sensor. Gas sensing properties of sensors were measured using a static system (CGS-1TP, Elite Tech Co., Ltd, Beijing, China). The sensor response was defined as the ratio of $R_{\mathrm{a}} / R_{\mathrm{g}}$, where $R_{\mathrm{a}}$ and $R_{\mathrm{g}}$ are the resistances of the sensor measured in air and test gas, respectively. The response and recovery times were defined as the time taken by the sensor to achieve $90 \%$ of the total resistance change in the case of air and $\mathrm{H}_{2} \mathrm{~S}$ gas.

\section{Results and discussion}

\subsection{Morphology and structure analysis}

The crystal structures of the pure $\mathrm{WO}_{3}$ and $\mathrm{Mo}_{x} \mathrm{~W}$ after annealing at $500{ }^{\circ} \mathrm{C}$ were determined by XRD in the range of 20 to $60^{\circ}$, as shown in Fig. 1(a). The detected diffraction peaks for $\mathrm{WO}_{3}$ and $\mathrm{Mo}_{2} \mathrm{~W}$ can be indexed to monoclinic phase of $\mathrm{WO}_{3}$ (JCPDS No. 43-1035), and no obvious characteristic peaks of $\mathrm{Mo}_{x} \mathrm{O}$ can be observed. However, for $\mathrm{Mo}_{4} \mathrm{~W}, \mathrm{Mo}_{6} \mathrm{~W}$ and $\mathrm{Mo}_{8} \mathrm{~W}$ samples, the XRD patterns include not only all the peaks of $\mathrm{WO}_{3}$, but also other peaks which are well consistent with (002), (101), (110), (10-3) and (11-3) lattice planes of $\mathrm{MoO}_{3}$ (JCPDS No. 47-1320), indicating the presence of Mo. Energy dispersive spectroscopy (EDS) was employed to further verify the element in $\mathrm{Mo}_{8} \mathrm{~W}$, as shown in Fig. 1(b). There is no other element was observed except for $\mathrm{O}, \mathrm{W}$ and Mo, confirming the purity of the products again.

The pure $\mathrm{WO}_{3}$ and $\mathrm{Mo}_{x} \mathrm{~W}$ samples were characterized by FESEM, showing that all samples exhibit a flower-like hierarchical structure with a diameter of about $1.2 \mu \mathrm{m}$ (Fig. 2(a)-(e)). Each hierarchical structure is assembled by numerous randomly ordered thin intersecting nanosheets and each nanosheet shows a thickness of around $40 \mathrm{~nm}$. It is obvious that the introduction of Mo element has no apparent morphological influence. Moreover, we can observe that $\mathrm{MoO}_{3}$ nanoparticles were successfully modified on the surface of nanosheets with the increase of Mo content. Meanwhile, the high resolution TEM was introduced to confirm the nanostructural features of $\mathrm{Mo}_{x} \mathrm{~W}$ composite microstructures. Fig. 2(f) and (g) show the HRTEM images of the $\mathrm{Mo}_{8} \mathrm{~W}$ sample, indicating the presence of the $\mathrm{MoO}_{3}$ and $\mathrm{WO}_{3}$ crystal lattices and an interplanar distances of $0.38 \mathrm{~nm}$ and $0.27 \mathrm{~nm}$, which corresponds to the (002) planes of $\mathrm{WO}_{3}$ (ref. 22) and (110) planes of $\mathrm{MoO}_{3}$, respectively. The results indicate that $\mathrm{MoO}_{3}$ nanoparticles have been dispersed randomly on the $\mathrm{WO}_{3}$ microstructures, which is in agreement with the XRD analyses.

To further determine the specific distribution of $\mathrm{O}, \mathrm{W}$ and Mo elements, EDS mapping was conducted on the sample of $\mathrm{Mo}_{8} \mathrm{~W}$. As shown in Fig. 3, we can clearly observe that the distribution of $\mathrm{O}$ and $\mathrm{W}$ elements are homogeneous and exhibits the identical spatial distributions (Fig. 3(b) and (c)). Moreover, the Mo element is uniform distribution in the $\mathrm{WO}_{3}$ microstructures (Fig. 3(d)), which indicates that Mo element is loaded on $\mathrm{WO}_{3}$ microstructures.
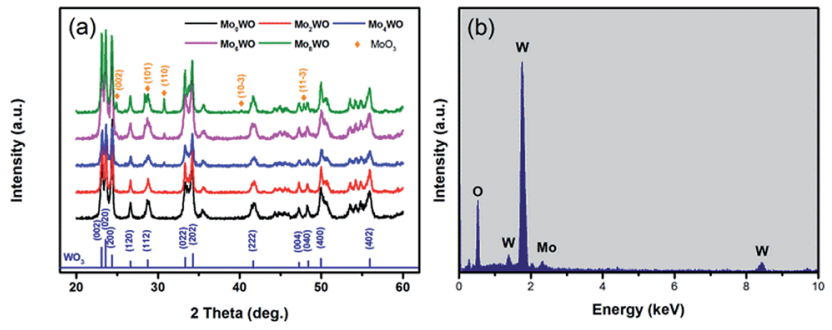

Fig. 1 (a) XRD patterns of the pure $\mathrm{WO}_{3}$ and $\mathrm{Mo}_{x} \mathrm{~W}$ samples. (b) EDS spectrum of $\mathrm{Mo}_{8} \mathrm{~W}$ sample. 


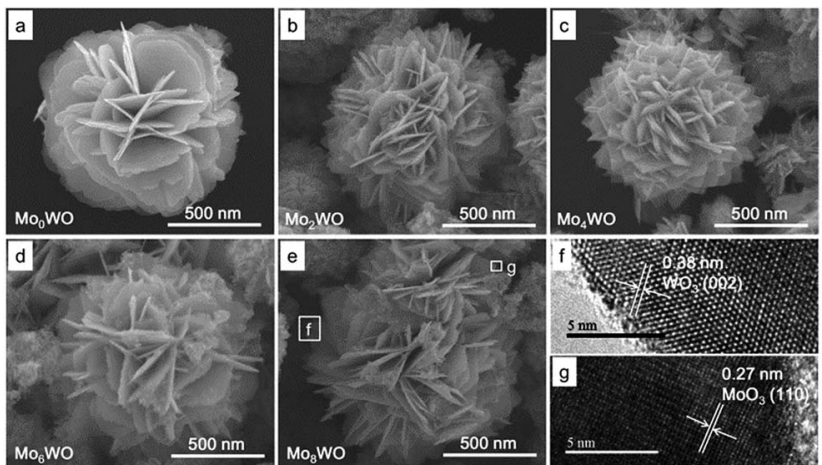

Fig. 2 SEM and HRTEM images of as-prepared samples, (a) pure $\mathrm{WO}_{3}$ (b) $\mathrm{Mo}_{2} \mathrm{~W}$, (c) $\mathrm{Mo}_{4} \mathrm{~W}$, (d) $\mathrm{Mo}_{6} \mathrm{~W}$, (e) $\mathrm{Mo}_{8} \mathrm{~W}$, (f and g) HRTEM images of the marked section in (e).
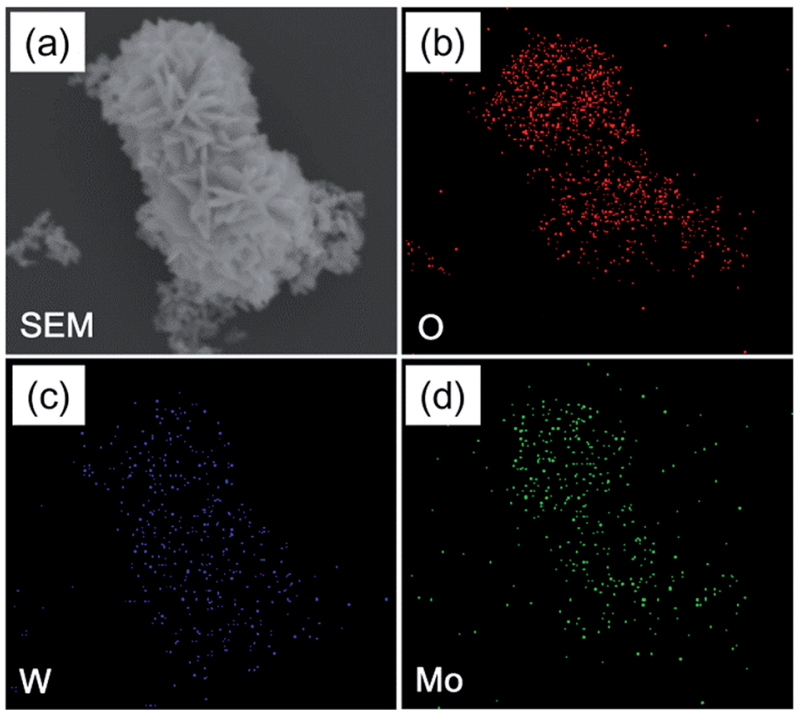

Fig. 3 (a) SEM images of $\mathrm{Mo}_{8} \mathrm{~W},(\mathrm{~b}-\mathrm{d})$ corresponding elemental mapping images for oxygen, tungsten, and molybdenum, respectively.

XPS measurements were also carried out on $\mathrm{Mo}_{6} \mathrm{~W}$ to analyze the chemical bond configuration and surface compositions of the $\mathrm{Mo}_{x} \mathrm{~W}$. The $\mathrm{C} 1 \mathrm{~s}$ peak located at $284.6 \mathrm{eV}$ is used as reference to calibrate the binding energy. Fig. 4(a) shows the lowresolution full range XPS spectrum of $\mathrm{Mo}_{6} \mathrm{~W}$, which demonstrates the presence of $\mathrm{W}, \mathrm{O}$ and Mo elements. The binding energies for $\mathrm{W} 4 \mathrm{f}_{7 / 2}$ and $\mathrm{W} 4 \mathrm{f}_{5 / 2}$ peaks were measured at 35.6 and $37.8 \mathrm{eV}$, which are close to the previous reports. ${ }^{23}$ Fig. $4(\mathrm{c})$ exhibits the high resolution XPS spectrum of $\mathrm{O} 1 \mathrm{~s}$ energy state with two distinct peaks centered at $529.9 \mathrm{eV}$ and $530.4 \mathrm{eV}$. The lower and higher binding energy peaks correspond to the bulk lattice oxygen and the chemisorbed oxygen ions including $\mathrm{O}^{-}$ and $\mathrm{O}_{2}{ }^{-}$in $\mathrm{WO}_{3}$, respectively. ${ }^{24}$ Fig. 4 (d) reveals the Mo 3d XPS spectrum, which including two peaks with binding energies at

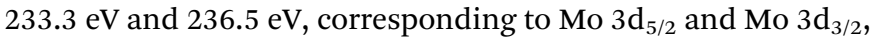
respectively. The XPS results indicated the existence of Mo element, which is consistent with the results of XRD and EDS. ${ }^{25}$
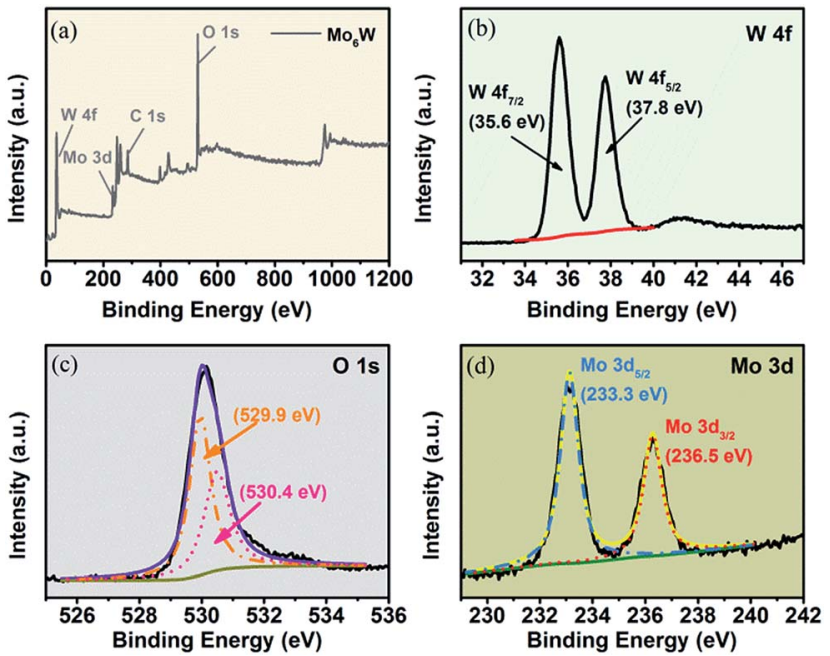

Fig. 4 XPS scan spectrum of sample $\mathrm{Mo}_{6} \mathrm{~W}$, (a) full scan spectrum and $(b-d)$ high resolution spectrum at $W 4 f, O 1 s$ and Mo $3 d$ state energies.

\subsection{Gas sensing characteristics}

Fig. 5 shows the responses of all the as-fabricated gas sensors to $10 \mathrm{ppm} \mathrm{H}_{2} \mathrm{~S}$ as a function of operating temperature ranging from $150{ }^{\circ} \mathrm{C}$ to $410{ }^{\circ} \mathrm{C}$. The responses of all the gas sensors initially increase with temperature, reach their maximum values at the optimum operating temperature of $250{ }^{\circ} \mathrm{C}$, and then dramatically decrease with the further increase of operating temperature. It is obvious that the operating temperature plays an important role in the gas sensing behavior, which can be explained from the kinetics and mechanics of gas adsorption-desorption on the surface of the $\mathrm{Mo}_{x} \mathrm{~W}$. When the operating temperature is too low, the chemical activation of $\mathrm{Mo}_{x} \mathrm{~W}$ is consequently small, which results in a very small response. When the operating temperature is too high, some adsorbed gas molecules maybe escape before reaction because of their enhanced activation, which will lead to a decrease of the response correspondingly. ${ }^{26}$ Moreover, the $\mathrm{Mo}_{x} \mathrm{~W}$ sensors show higher responses, and the $\mathrm{Mo}_{6} \mathrm{~W}$ sensor exhibits the highest response of 28.5 to $10 \mathrm{ppm}_{2} \mathrm{~S}$, which is about 2.6 times higher than that of pure $\mathrm{WO}_{3}$ sensor (10.8). The measured results

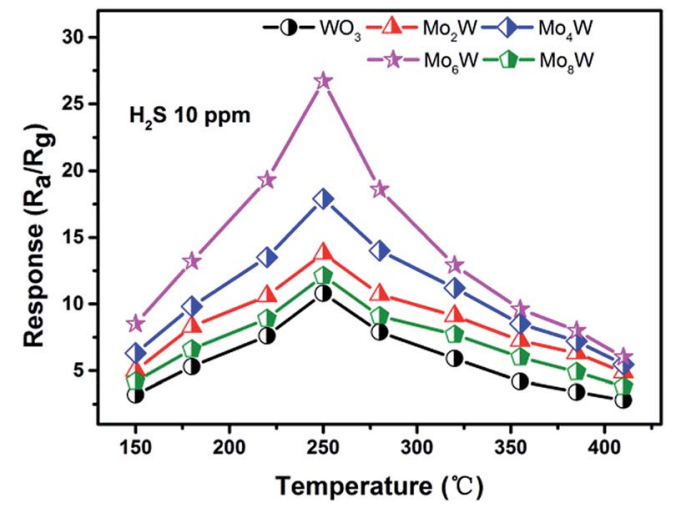

Fig. 5 Response vs. operating temperature of samples to $10 \mathrm{ppm} \mathrm{H}_{2} \mathrm{~S}$. 
indicate that the introduction of $\mathrm{MoO}_{3}$ is advantageous to improve the sensing property of $\mathrm{WO}_{3}$ gas sensor, and the asprepared $\mathrm{Mo}_{6} \mathrm{~W}$ sensor exhibits excellent gas sensing performances toward $\mathrm{H}_{2} \mathrm{~S}$ detection.

Fig. 6(a)-(e) presents the response transients of the gas sensors based on pure $\mathrm{WO}_{3}$ and $\mathrm{Mo}_{x} \mathrm{~W}$ to different concentrations of $\mathrm{H}_{2} \mathrm{~S}$ gas at the optimum operating temperature. For each cycle, the response increased immediately after exposure to $\mathrm{H}_{2} \mathrm{~S}$ gas and then recovered rapidly to its initial state after $\mathrm{H}_{2} \mathrm{~S}$ gas removing. The results indicate that the response and recovery characteristics were almost reproducible within a short time. The responses vs. concentrations curves were plotted out to further understand the relationship between the responses and the concentrations of $\mathrm{H}_{2} \mathrm{~S}$ gas, as shown in Fig. 6(f). The gas response values increase with the increase of gas concentration in the range of 0.05-10 ppm, and the sensors can detect even down to 50 ppb with high responses. Especially, the response of the gas sensor based on $\mathrm{Mo}_{6} \mathrm{~W}$ towards $50 \mathrm{ppb} \mathrm{H}_{2} \mathrm{~S}$ can reach to 8.5. However, when the gas concentration is above $4 \mathrm{ppm}$, the gas responses increase slowly, which suggests that the gas sensors become saturated at higher concentration of $\mathrm{H}_{2} \mathrm{~S}$ gas. From the relationship between concentrations and responses of the as-fabricated sensors, it was found that the $\mathrm{Mo}_{x} \mathrm{~W}$ sensors exhibit enhanced gas sensing properties than pure $\mathrm{WO}_{3}$ sensor. By comparing, gas sensor based on $\mathrm{Mo}_{6} \mathrm{~W}$ shows the highest response on each concentration of $\mathrm{H}_{2} \mathrm{~S}$ among all the as-fabricated gas sensors. Meanwhile, in order to determine the detection limit, the gas sensing
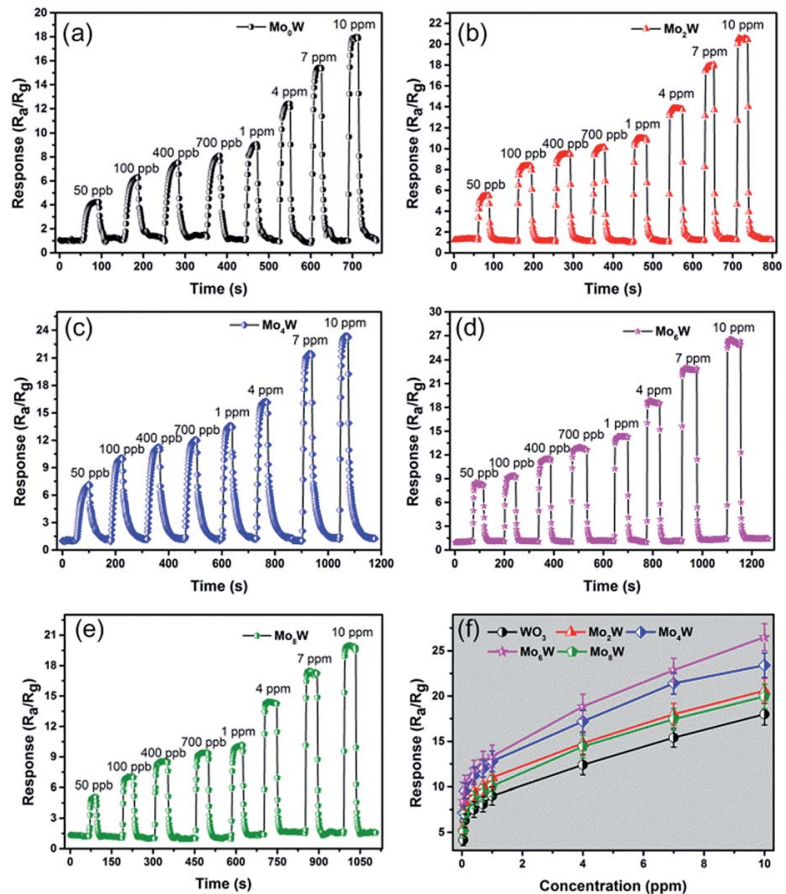

Fig. 6 Response of as-prepared gas sensors to different concentrations of $\mathrm{H}_{2} \mathrm{~S}$, (a) pure $\mathrm{WO}_{3}$, (b) $\mathrm{Mo}_{2} \mathrm{~W}$, (c) $\mathrm{Mo}_{4} \mathrm{~W}$, (d) $\mathrm{Mo}_{6} \mathrm{~W}$, (e) $\mathrm{Mo}_{8} \mathrm{~W}$, and (f) responses vs. $\mathrm{H}_{2} \mathrm{~S}$ concentrations curves for all the as-fabricated gas sensors.

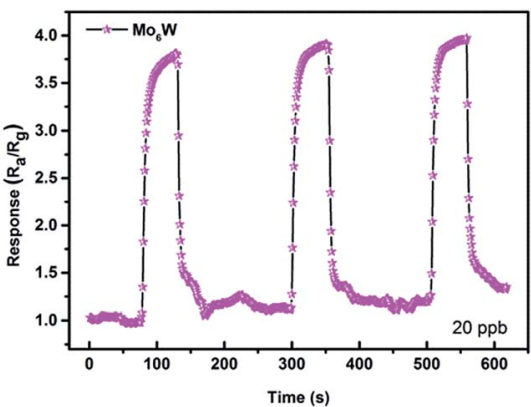

Fig. 7 Dynamic response curves of $\mathrm{Mo}_{6} \mathrm{~W}$-based gas sensor toward $20 \mathrm{ppb} \mathrm{H}_{2} \mathrm{~S}$ at $250{ }^{\circ} \mathrm{C}$.

experiments were conducted on the $\mathrm{Mo}_{6} \mathrm{~W}$ toward $20 \mathrm{ppb}$ of $\mathrm{H}_{2} \mathrm{~S}$, as shown in Fig. 7. The response value can reach to 4, which indicates that the $\mathrm{Mo}_{6} \mathrm{~W}$ is a potential material for lower $\mathrm{H}_{2} \mathrm{~S}$ detection.

Fig. 8(a) illustrates the typical dynamic resistance curves of all the as-fabricated gas sensors to $10 \mathrm{ppm}_{2} \mathrm{~S}$ at $250{ }^{\circ} \mathrm{C}$. The resistance of gas sensors decreased sharply when exposure to $\mathrm{H}_{2} \mathrm{~S}$ due to the reducing nature. Fig. 7(b) shows the detailed information of response/recovery times for all the sensors, demonstrating their quick response-recovery characteristics to $\mathrm{H}_{2} \mathrm{~S}$ gas. Especially, the gas sensor based on $\mathrm{Mo}_{6} \mathrm{~W}$ exhibits a fast response/recovery time $(2 \mathrm{~s} / 5 \mathrm{~s})$ among all the asfabricated gas sensors. Furthermore, the response time and recovery time of all the gas sensors as a function of the $\mathrm{H}_{2} \mathrm{~S}$ concentration are shown in Fig. 9(a) and (b). Both response and recovery time decrease and finally stay in a relative stable value with increasing the gas concentration.

The selectivity of the gas sensor based on $\mathrm{Mo}_{6} \mathrm{~W}$ was also investigated by exposing to $100 \mathrm{ppm}$ various gases, including hydrogen sulphide $\left(\mathrm{H}_{2} \mathrm{~S}\right)$, ethanol, acetone, toluene, formaldehyde, isopropanol, methyl alcohol and ammonium hydroxide at $250{ }^{\circ} \mathrm{C}$, as shown in Fig. 10. Obviously, the sensor shows considerably less responsive to other gases than $\mathrm{H}_{2} \mathrm{~S}$. The measured response to $100 \mathrm{ppm}_{2} \mathrm{~S}$ can reach to 560, which is about 28 times and 270 times higher than that of ethanol and toluene, respectively. Conclusively, the results indicate that the $\mathrm{Mo}_{6} \mathrm{~W}$ composite microstructures can be used as a promising material for high performance detection of $\mathrm{H}_{2} \mathrm{~S}$. A comparable survey of the gas sensing performances between ours and other $\mathrm{WO}_{3}$-based sensors are listed in Table 1 . Apparently, the $\mathrm{Mo}_{6} \mathrm{~W}$ -
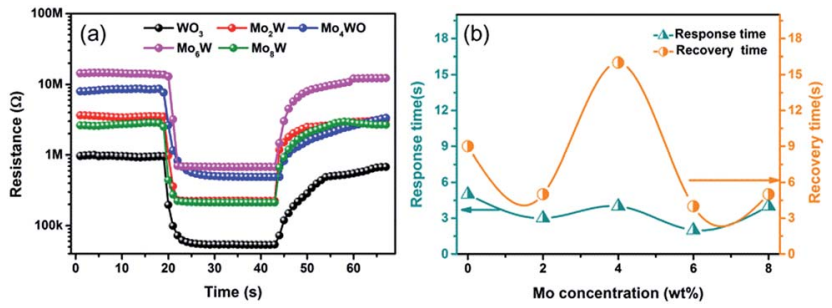

Fig. 8 (a) Resistance transients and (b) response/recovery time of all the as-fabricated gas sensors to $10 \mathrm{ppm} \mathrm{H}_{2} \mathrm{~S}$. 

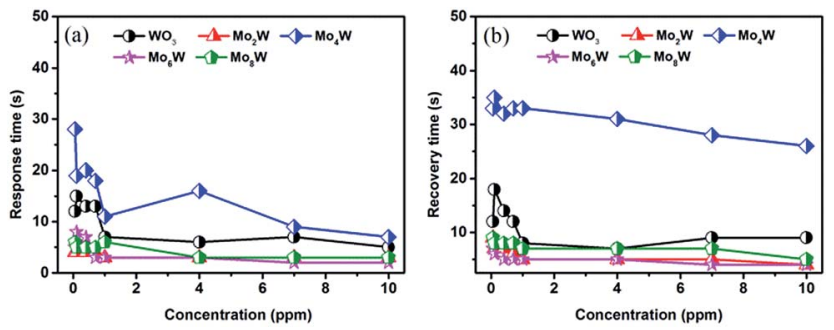

Fig. 9 (a) Response time and (b) recovery time of all the as-fabricated gas sensors as a function of the $\mathrm{H}_{2} \mathrm{~S}$ concentration.

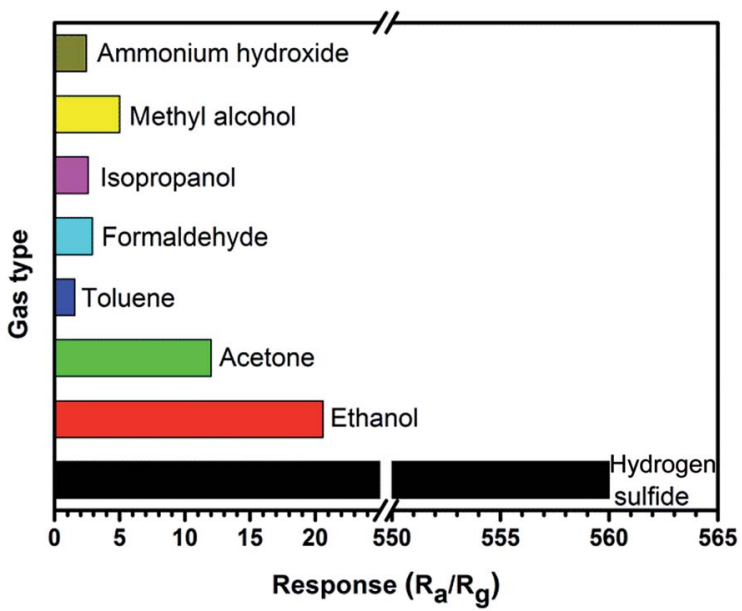

Fig. 10 Selectivity of $\mathrm{MO}_{6} \mathrm{~W}$-based gas sensor to different kinds of gases at $100 \mathrm{ppm}$ at $250^{\circ} \mathrm{C}$.

based gas sensor exhibits a lower optimum working temperature and fastest response-recovery time than those in the reported literatures. ${ }^{27-34}$

\subsection{Gas sensing mechanism}

It is known that the gas sensing mechanism of $\mathrm{WO}_{3}$ is surfacecontrolled type, and associates with the chemisorbed oxygen ions. For pure $\mathrm{WO}_{3}$, oxygen molecules on the surface will become oxygen ions through trapping electrons from the conduction bond of $\mathrm{WO}_{3}$, resulting in a decrease of carriers and increase the depletion layer. Thus, the resistance of $\mathrm{WO}_{3}$ would be in a high level. When the $\mathrm{WO}_{3}$ is exposed in $\mathrm{H}_{2} \mathrm{~S}$ gas, the oxygen ions in the surface will react with $\mathrm{H}_{2} \mathrm{~S}$ molecules, produce $\mathrm{SO}_{2}$ and $\mathrm{H}_{2} \mathrm{O}$, and release electron back to the conduction bond of $\mathrm{WO}_{3}$, which cause the decrease of electric resistance of $\mathrm{WO}_{3}$. This process can be expressed in the following reaction: ${ }^{31,35}$

$$
\mathrm{H}_{2} \mathrm{~S}+\mathrm{O}^{-}{ }_{(\text {ads })} \rightarrow \mathrm{H}_{2} \mathrm{O}+\mathrm{SO}_{2}+\mathrm{e}^{-}
$$

The excellent gas sensing performance of the $\mathrm{Mo}_{x} \mathrm{~W}$ samples might be ascribed to the heterojunction structure between $\mathrm{WO}_{3}$ and $\mathrm{MoO}_{3}$, which is similar to that reported previously ${ }^{36,37}$ At the interface of $\mathrm{MoO}_{3}$ and $\mathrm{WO}_{3}$, the electrons move from $\mathrm{WO}_{3}$ to $\mathrm{MoO}_{3}$ until the Fermi levels align, since the different work functions as shown in Fig. 11(a). ${ }^{18,38}$ Consequently, a thicker electron depletion layer forms at the interface between $\mathrm{MoO}_{3}$ and $\mathrm{WO}_{3}$, as shown in Fig. 11(b). $\mathrm{Mo}_{x} \mathrm{~W}$ has a higher initial resistance in air and releases more electrons into the conduction band of $\mathrm{WO}_{3}$ when exposed to $\mathrm{H}_{2} \mathrm{~S}$ ambient (Fig. 11(c)), resulting in larger resistance change (higher response) compared to the pure $\mathrm{WO}_{3}$. We found that when the weight percentage of Mo element is about 6 , the $\mathrm{Mo}_{x} \mathrm{~W}$ shows the maximum gas sensitivity, indicating that appropriate $\mathrm{MoO}_{3}$ can significantly enhance the gas sensing properties. ${ }^{39}$

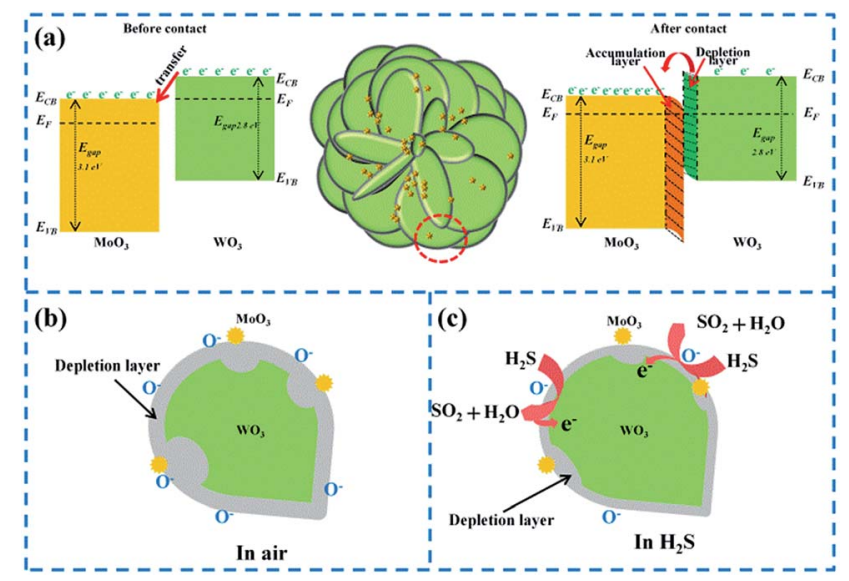

Fig. 11 Schematic illustration for $\mathrm{Mo}_{x} \mathrm{~W}$ exposed to air and $\mathrm{H}_{2} \mathrm{~S}$ gas ambient.

Table $1 \mathrm{H}_{2} \mathrm{~S}$ sensing performances based on different $\mathrm{WO}_{3}$ structures






\section{Conclusions}

Pure $\mathrm{WO}_{3}$ and $\mathrm{MoO}_{3} @ \mathrm{WO}_{3}$ composite microstructures were successfully synthesized through hydrothermal and impregnation method. The crystal structure and morphology of the asprepared samples were characterized and analyzed. Gas sensing performances of pure and $\mathrm{MoO}_{3} @ \mathrm{WO}_{3}$ composite microstructures towards hydrogen sulfide gas were also investigated and compared. The measurement results reveal that the gas sensor based on $\mathrm{Mo}_{6} \mathrm{~W}$ has the a high sensitivity, a quick response/recovery time and a good selectivity to hydrogen sulfide at the optimum operating temperature of $250{ }^{\circ} \mathrm{C}$, which is a highly promising material for gas sensing applications.

\section{Acknowledgements}

This work was supported by the National Natural Science Foundation of China (51205274), the National Natural Science of Shanxi Province Science (2016011039), the Talent project of Shanxi Province (201605D211020), Higher School Science and Technology Innovation Project of Shanxi (2016137), the Graduate Education Innovation Fund (02100738), the Technology Major Project of the Shanxi and Technology Department (20121101004) and the Key Disciplines Construction in Colleges and Universities of Shanxi ([2012]45).

\section{Notes and references}

1 X. Liu, S. Du, Y. Sun, M. Yu, W. Tang, C. Chen, L. Sun, B. Yang, W. W. Cao and M. N. R. Ashfold, ACS Appl. Mater. Interfaces, 2016, 8, 16379-16385.

2 Y. J. Chen, X. M. Gao, X. P. Di, Q. Y. Quyan, P. Gao, L. H. Qi, C. Y. Li and C. L. Zhu, ACS Appl. Mater. Interfaces, 2013, 5, 3267-3274.

3 Z. S. Hosseini, A. Irajizad and A. Mortezaali, Sens. Actuators, $B, 2015,207,865-871$.

4 R. Tabassum and B. D. Gupta, Appl. Opt., 2015, 54, 1032-1040.

5 T. Hübert, L. Boon-Brett, G. Black and U. Banach, Sens. Actuators, B, 2011, 157, 329-352.

6 E. Brauns, E. Morsbach, S. Kunz, M. Bäumer and W. Lang, Sens. Actuators, B, 2014, 193, 895-903.

7 N. Barsan, D. Koziej and U. Weimar, Sens. Actuators, B, 2007, 121, 18-35.

8 M. Yuasa, K. Suematsu, K. Yamada, K. Watanabe, T. kida, N. Yamazoe and K. Shimanoe, Cryst. Growth Des., 2016, 16, 4203-4208.

9 K. Hagedorn, W. Y. Li, Q. J. Liang, S. Dilger, M. Noebels, M. R. Wagner, J. S. Reparaz, A. Dollinger, J. S. Günne, T. Dekorsy, L. Schmidt-Mende and S. polarz, Adv. Funct. Mater., 2016, 26, 3424-3437.

10 Y. J. Zhang, D. K. Zhang, W. M. Guo and S. J. Chen, J. Alloys Compd., 2016, 685, 84-90.

11 J. W. Yoon, J. S. Kim, T. H. Kim, Y. J. Hong, Y. C. Kang and J. H. Lee, Small, 2016, 12, 4229-4240.

12 A. A. Khaleed, A. Bello, J. K. Dangbegon, D. Y. Momodu, M. J. Madito, F. U. Ugbo, A. A. Akande, B. P. Dhonge,
F. Barzegar, O. Olaniyan, B. W. Mwakikunga and N. Manyala, J. Alloys Compd., 2017, 694, 155-162.

13 K. H. Kim, S. J. Kim, H. J. Cho, N. H. Kim, J. S. Jang, S. J. Choi and Il. D. Kim, Sens. Actuators, B, 2017, 241, 1276-1282.

14 Y. Yao, F. X. Ji, M. L. Yin, X. P. Ren, Q. Ma, J. Q. Yan and S. Z. F. Liu, ACS Appl. Mater. Interfaces, 2016, 8, 18165-18172.

15 T. Kida, A. Nishiyama, Z. Q. Hua, K. Suematsu, M. Yuasa and K. Shimanoe, Langmuir, 2014, 30, 2571-2579.

16 Y. D. Zhang, W. W. He, H. X. Zhao and P. J. Li, Vacuum, 2013, 95, 30-34.

17 M. L. Yin, L. M. Yu and S. Z. Liu, J. Alloys Compd., 2017, 696, 490-497.

18 X. J. Yang, V. Salles, Y. Kaneti, M. S. Liu, M. Maillard, C. Joumet, X. C. Jiang and A. Brioude, Sens. Actuators, B, 2015, 220, 1112-1119.

19 X. D. Zhao, H. M. Ji, Q. Q. Jia and M. J. Wang, J. Mater. Sci.: Mater. Electron., 2015, 26, 8217-8223.

20 W. W. Guo and Z. C. Wang, Mater. Lett., 2016, 169, 246-249. 21 P. Gao, H. M. Ji, Y. G. Zhou and X. L. Li, Thin Solid Films, 2012, 520, 3100-3106.

22 K. Huang, Q. Zhang, F. Yang and D. Y. He, Nano Res., 2010, 3, 281-287.

23 Y. H. Yang, F. Q. Zhan, H. Li, W. H. Liu and S. Yu, J. Solid State Electrochem., 2017, DOI: 10.1007/s10008-017-3569-4.

24 Y. Wang, Z. T. Zhao, Y. J. Sun, P. W. Li, J. L. Ji, Y. Chen, W. D. Zhang and J. Hu, Sens. Actuators, B, 2017, 240, 664-673.

25 J. Swiatowska-Mrowiecka, S. deDiesbach, V. Maurice, S. Zanna, L. Klein, E. Briand, I. Vickridge and P. Marcus, J. Phys. Chem. C, 2008, 112, 11050-11058.

26 L. Liu, S. C. Li, J. Zhang, L. Y. Wang, J. B. Zhang, H. Y. Li, Z. Liu, Y. Han, X. X. Zhang and P. Zhang, Sens. Actuators, $B, 2011,155,782-788$.

27 N. M. Vuong, D. Kim and H. Kim, Sci. Rep., 2015, 5, 11040.

28 N. H. Kim, S. J. Choi, D. J. Yang, J. Bae, J. Park and D. Kim, Sens. Actuators, B, 2014, 193, 574-581.

29 F. E. Annanouch, Z. Haddi, S. Vallejos, P. Umek, P. Guttmann, C. Bittencourt and E. Llobet, ACS Appl. Mater. Interfaces, 2015, 7, 6842-6851.

30 S. J. Choi, F. Fuchs, R. Demadrille, B. Grevin, B. H. Jang, S. J. Lee, J. H. Lee, L. H. Tuller and D. Kim, ACS Appl. Mater. Interfaces, 2014, 6, 9061-9070.

31 P. G. Su and Y. T. Peng, Sens. Actuators, B, 2014, 193, 637-643. 32 K. Galatsis, Y. X. Li, W. Wlodarski, E. Comini, G. Sberveglieri, C. Cantalini, S. Santucci and M. Passacantando, Sens. Actuators, B, 2002, 83, 276-280.

33 K. Galatsis, Y. X. Li, W. Wlodarski and K. Kalantar-zadeh, Sens. Actuators, B, 2001, 77, 478-483.

34 C. N. Xu, N. Miura, Y. Ishida, K. Matsuda and N. Yamazoe, Sens. Actuators, B, 2000, 65, 163-165.

35 R. H. Bari, S. B. Patil and A. R. Bari, Int. Nano Lett., 2013, 12, 1-5. 36 P. Li, H. Q. Fan and Y. Cai, Sens. Actuators, B, 2013, 185, 110-116. 37 W. L. Zang, Y. X. Nie, D. Zhu, P. Deng, L. L. Xing and X. Y. Xue, J. Phys. Chem. C, 2014, 118, 9209-9216.

38 M. Ahsan, M. Z. Ahmad, T. Tesfamichael, J. Bell, W. Wlodarski and N. Motta, Sens. Actuators, B, 2012, 173, 789-796.

39 C. B. Liu, H. Shan, L. Liu, S. C. Li and H. Y. Li, Ceram. Int., 2014, 40, 2395-2399. 